\title{
Microstructural Influences on Very-High-Cycle Fatigue-Crack Initiation in Ti-6246
}

\author{
C.J. SZCZEPANSKI, S.K. JHA, J.M. LARSEN, and J.W. JONES
}

The fatigue behavior of an alpha + beta titanium alloy, Ti-6Al-2Sn-4Zr-6Mo, has been characterized in the very-high-cycle fatigue (VHCF) regime using ultrasonic-fatigue $(20 \mathrm{kHz})$ techniques. Stress levels $\left(\sigma_{\max }\right)$ of 40 to 60 pct of the yield strength of this alloy have been examined. Fatigue lifetimes in the range of $10^{6}$ to $10^{9}$ cycles are observed, and fatigue cracks initiate from both surface and subsurface sites. This study examines the mechanisms of fatiguecrack formation by quantifying critical microstructural features observed in the fatigue-crack initiation region. The fracture surface near the fatigue-crack-initiation site was crystallographic in nature. Facets, which result from the fracture of primary alpha $\left(\alpha_{p}\right)$ grains, are associated with the crack-initiation process. The $\alpha_{p}$ grains that form facets are typically larger in size than average. The spatial distribution of $\alpha_{p}$ grains relative to each other observed near the initiation site did not correlate with fatigue life. Furthermore, the spatial distribution of $\alpha_{p}$ grains did not provide a suitable means for discerning crack-initiation sites from randomly selected nominal areas. Stereofractography measurements have shown that the facets observed at or near the initiation sites are oriented for high shear stress; i.e., they are oriented close to $45 \mathrm{deg}$ with respect to the loading axis. Furthermore, a large majority of the grains and laths near the site of crack initiation are preferentially oriented for either basal or prism slip, suggesting that regions where $\alpha_{p}$ grains and $\alpha$ laths have similar crystallographic orientations favor crack initiation. Microtextured regions with favorable and similar orientations of $\alpha_{p}$ grains and the lath $\alpha$ are believed to promote cyclic-strain accumulation by basal and prism slip. Orientation imaging microscopy (OIM) indicates that these facets form on the basal plane of $\alpha_{p}$ grains. The absence of a significant role of spatial clustering of $\alpha_{p}$ grains, coupled with the observation of regions of microtexture on the order of 300 to $500 \mu \mathrm{m}$ supports the idea that variability in fatigue life in the very-high-cycle fatigue regime results from the variability in the nature (intensity, coherence, and size) of these microtextured regions.

DOI: $10.1007 / \mathrm{s} 11661-008-9633-\mathrm{z}$

(C) The Minerals, Metals \& Materials Society and ASM International 2008

\section{INTRODUCTION}

THE study of very-high-cycle fatigue (VHCF) behavior is attracting increased interest from industry because many components in structural applications, such as automobile cylinder heads, engine blocks, ${ }^{[1]}$ and turbine engines, will accumulate $10^{8}$ to $10^{10}$ cycles in service. The conventional approach of designing components to a fatigue limit is not applicable in VHCF because fatigue failures have been observed ${ }^{[2]}$ below the

C.J. SZCZEPANSKI, Graduate Student Researcher, is with the Materials Science and Engineering Department, University of Michigan, Ann Arbor, MI 48109, and the Air Force Research Laboratory, Materials and Manufacturing Directorate, AFRL/ RXLMN, Wright-Patterson Air Force Base, OH 45433. Contact e-mail: christopher.szczepanski@wpafb.af.mil S.K. JHA, Research Scientist, is with the Universal Technology Corporation, Dayton, $\mathrm{OH}$ 45432. J.M. LARSEN, Senior Scientist, is with the Air Force Research Laboratory, Materials and Manufacturing Directorate, AFRL/RXLMN, Wright-Patterson Air Force Base, OH 45433. J.W. JONES, Arthur F. Thurnau Professor, is with the Materials Science and Engineering Department, University of Michigan, Ann Arbor, MI 48109.

Manuscript submitted on March 3, 2008.

Article published online August 28, 2008 conventional fatigue limit. This has led some research$\mathrm{ers}^{[3]}$ to propose a modified stress-life $(\mathrm{SN})$ curve where surface-initiated fatigue failures are observed at high stresses, and subsurface fatigue-crack initiation is observed at very long lifetimes below the conventional fatigue limit. Mughrabi ${ }^{[4]}$ explained failures below the conventional fatigue limit in terms of fundamental physical mechanisms of fatigue-damage accumulation by suggesting that, even though macroscopic strain in VHCF is below the persistent slip band threshold, slip irreversibility can still accumulate and lead to failure. This agrees with the work of Lukáš and $\mathrm{Kunz}^{[5]}$ who argue that in the VHCF regime the applied strain is nominally elastic, and only localized plastic deformation will accumulate at specific microstructural locations. Thus, as compared to low cycle fatigue where the majority of grains accommodate some plastic deformation, in the longer lifetime regimes of high-cycle fatigue (HCF) and VHCF (i.e., $\geq 10^{6}$ cycles), it is likely that specific microstructural configurations can be associated with more rapid local fatigue-damage accumulation. Such fatigue-critical microstructural neighborhoods have been defined based on grain size ${ }^{[9]}$ spatial orientation, ${ }^{[9,10]}$ proximity to the specimen surface, ${ }^{[3,6]}$ and crystallographic orientation. ${ }^{[7,17]}$ The current work 
examines which of these factors, if any, contribute to the process of fatigue-crack initiation in the $\alpha+\beta$ titanium alloy Ti-6Al-2Sn-4Zr-6Mo.

Much of the literature on fatigue-crack initiation in $\alpha+\beta$ titanium alloys focuses on analysis of the fracture surfaces to determine the deformation and possible strain-accumulation mechanisms that are responsible for crack initiation. In materials that do not contain inclusions or porosity, fatigue cracks tend to initiate in locations where the local microstructure promotes the accumulation of irreversible slip. Hall's review ${ }^{[8]}$ of fatigue-crack initiation in $\alpha+\beta$ titanium alloys established that fatigue damage typically accumulates in the alpha phase. Further, the length scale of the deformation will vary depending on the microstructure and processing conditions. Fatigue-critical microstructural features have been identified as individual $\alpha_{p}$ grains, $\alpha$ colonies, prior $\beta$ grains, or regions of similarly oriented $\alpha$ grains. Mahajan and Margolin ${ }^{[9]}$ found that, in Ti-6246, fatigue cracks initiated in large alpha grains or in areas where a number of alpha grains was clustered, which presumably increased the slip length. They hypothesized that a likely method for improving the fatigue resistance of this alloy is to increase the spacing between alpha grains or to refine the $\alpha_{p}$ grain size to limit slip transmission between $\alpha_{p}$ grains or plastic deformation within grains, respectively. Researchers have investigated clustering both in a statistical $^{[10]}$ and a micromechanistic ${ }^{[11]}$ approach. Chandran and $\mathrm{Jha}^{[10]}$ determined that $\alpha_{p}$ clustering is the fatiguecritical microstructural feature in Ti-10V-2Fe-3Al in one population of failures, and they were able to model this using Poisson defect statistics. In Waspaloy (Inco Alloys, Int., Huntington, WV), Davidson et al. ${ }^{[1]}$ found that the crack-initiation sites are associated with clusters of similarly-oriented grains, which they termed "supergrains." They suggested that supergrains were more susceptible to fatigue-crack initiation because localized deformation in one grain could be more easily accommodated in adjacent grains due to their similar crystallographic orientation. Regions of material with similar crystallographic orientation are commonly observed to initiate fatigue cracks in titanium alloys, as well. ${ }^{[7,8,12,17]}$ Bieler and Semiatin ${ }^{[13]}$ established that the presence of these microtextured regions results from local heterogeneities in deformation during thermomechanical processing.

Macroscopic textures, resulting from the processing history of titanium alloys, are known to influence mean fatigue properties. ${ }^{[14,15]}$ However, in the regime of VHCF, damage accumulation will only occur if the local microstructure is suitable for irreversible slip to accumulate. In other words, microstructural heterogeneity is thought to cause scatter in fatigue lifetimes. Evidence of such behavior has been observed by a number of researchers who have investigated the effect of local texture on fatigue-crack initiation ${ }^{[7,17]}$ and propagation $^{[16]}$ in titanium alloys. In Ti-6242, Sinha et al. ${ }^{[17]}$ have found that dwell-fatigue loading, in which specimens are held at a static load as part of every fatigue cycle, leads to crack formation in microtextured regions suitable for basal slip that are surrounded by regions of material oriented for prism slip. Multiple cracks initiated, and while the dominant crack was not necessarily the first to initiate, they did grow out of the largest microtextured region. In the work of LeBiavant et al., ${ }^{[7]}$ numerous cracks were found to initiate in macrozones where the majority of $\alpha_{p}$ grains were oriented for basal or prism slip. Each of these studies aimed to understand the contribution of heterogeneous texture to the initiation and growth of fatigue cracks in the HCF regime. The objective of the current work is to establish which microstructural features and configurations cause fatigue-crack initiation in the VHCF regime to better understand the mechanisms of damage accumulation and fatigue-crack initiation.

\section{MATERIALS AND EXPERIMENTAL PROCEDURES}

The material used in this study was Ti-6Al-2Sn-4Zr$6 \mathrm{Mo}$ (wt pct), which is commonly referred to as Ti-6246. Typical processing conditions ${ }^{[18]}$ were used to produce bimodal microstructures consisting of equiaxed alpha grains in a transformed beta matrix, as shown by the micrographs in Figure 1. The average $\alpha_{p}$ grain size measured using the linear-intercept method is $3.7 \mu \mathrm{m} \pm 2.6 \mu \mathrm{m}$. As Figure 2 shows, the variation in $\alpha_{p}$ grain size follows a log-normal distribution. The area fraction of $\alpha_{p}$ grains was approximately $30 \mathrm{pct}$, and within the transformed beta regions, the area fraction of lath $\alpha$ was measured as 50 pct, resulting in a total-area fraction of alpha near 65 pet $\left(30\right.$ pct $\alpha_{p}$ and 35 pct lath $\alpha$ ). Area fractions were measured using the point-count method and verified with commercially available computational image-analysis tools. The yield stress of this material was measured to be $1160 \mathrm{MPa}$.

Specimens were cut circumferentially from a forged pancake that was processed to simulate forging conditions in an actual component. Cylindrical specimen blanks were cut from this material, and grip ends of

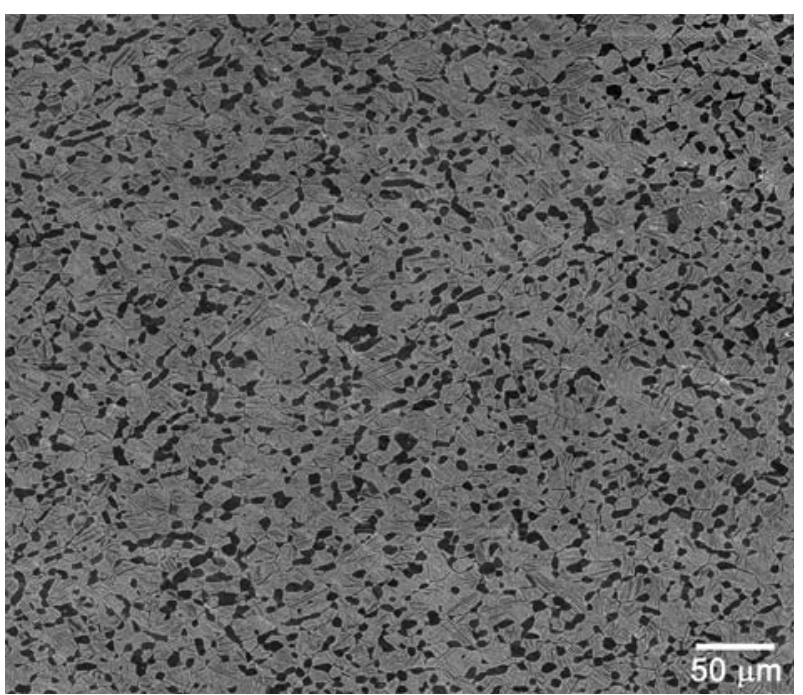

Fig. 1-Secondary electron micrograph of a nominal microstructural area that displays the equiaxed $\alpha_{p}$ grains in a transformed $\beta$ matrix. 


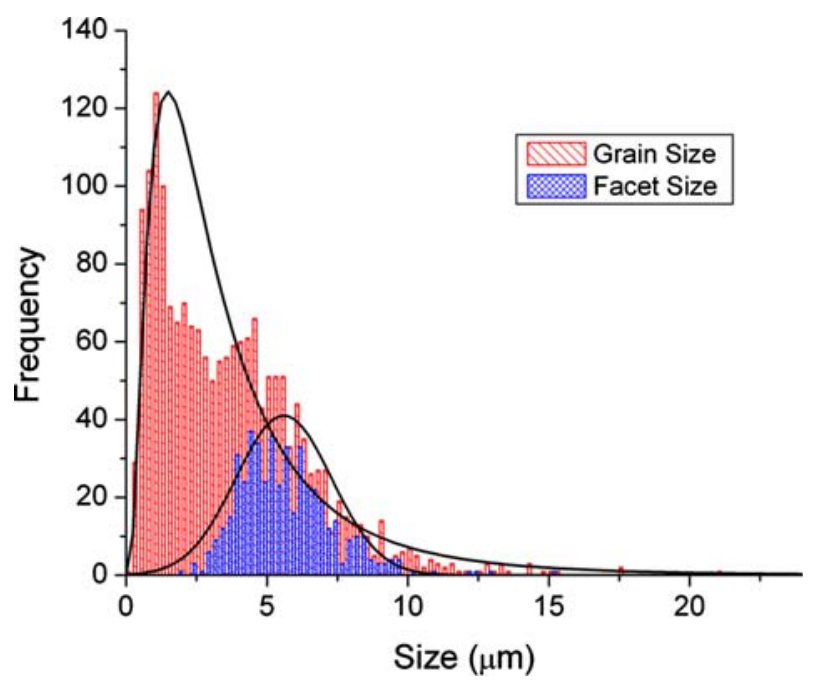

Fig. 2-The histogram of $\alpha_{p}$-grain size and $\alpha_{p}$-facet size depicts the distribution of feature sizes measured in this investigation. Color figure available online.

Ti-6Al-4V rod were inertia welded onto the specimen blanks. Final machining of cylindrical specimens was completed by low-stress grinding to minimize compressive residual stresses. ${ }^{[19]}$ All specimens were then electropolished to remove the remaining surface compressive residual stresses. The gage was $4 \mathrm{~mm}$ in diameter and $12 \mathrm{~mm}$ in length. Axial fatigue testing was completed using ultrasonic-fatigue techniques detailed elsewhere. ${ }^{[20-22]}$ Specimens were designed such that their resonant frequency was approximately $20 \mathrm{kHz}$.

Observation of the fracture surfaces was completed using two scanning electron microscopes (SEMs): a Leica Cambridge S360FE microscope (Leica Microsystems $\mathrm{GmbH}$, Wetzlar, Germany) operating at a probe current of $100 \mathrm{pA}$ and accelerating voltage of $20 \mathrm{kV}$, and a PHILIPS* XL30FEG operating at $10 \mathrm{kV}$ with a

*PHILIPS is a trademark of FEI, Hillsboro, OR.

probe current of approximately $2 \mathrm{nA}$. Orientation imaging microscopy (OIM) was performed on polished sections of the fractured fatigue specimens using these two microscopes with detectors manufactured by EDAX-TSL (Ametek, Mahwah, NJ). For the OIM investigations, the probe current and accelerating voltage were approximately $10 \mathrm{nA}$ and $20 \mathrm{kV}$, respectively.

Orientation imaging microscopy scans were completed on the region of material just below the fracture surfaces at the site of fatigue-crack initiation. The section of material that was exposed for OIM analysis is depicted as plane B-B in Figure 3. Figure 3 also illustrates the reference frame for OIM scans. The OIM scans have been acquired in the RD-TD plane with RD corresponding to the tensile axis of the fatigue specimens. The advantage of sectioning samples to expose this plane is that the fracture surface and the microstructure just below the crack-initiation site (A) can be viewed simultaneously. These pieces containing the
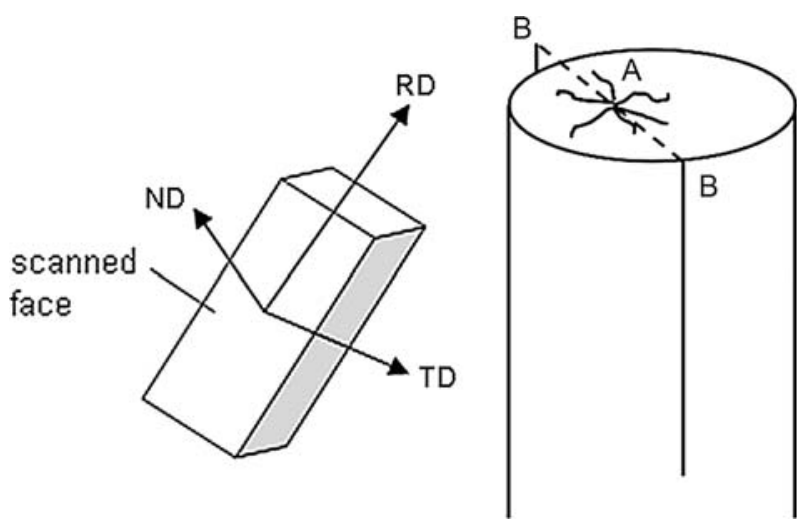

Fig. 3-Schematic of sectioning plane for orientation relative to loading axis at crack-initiation site. RD corresponds to the loading axis, while plane B-B corresponds to the RD-TD plane.

fracture surface were then mounted in epoxy and mechanically polished. Material-removal depth was monitored with a micrometer. As the desired plane for observation was approached, the specimen was placed in a vibratory polisher to perform a final low-stress polishing in a $0.05-\mu \mathrm{m}$ solution of colloidal silica. This final polishing step was critical to the acquisition of reliable OIM data. The epoxy mount was then dissolved in acetone to allow simultaneous imaging in the SEM of the fracture surface and the polished section below the site of crack initiation.

To gain insight into the process of crack initiation, the spatial orientations of facets were measured with respect to the loading axis using stereography. Images used to produce three-dimensional (3-D) reconstructions of fracture surfaces were acquired in the SEM by centering the feature of interest in the field of view at the eucentric height. Images were then acquired at tilt angles of 0 and $6 \mathrm{deg}$ with respect to the stage normal position for each facet. The technique and procedure for generating stereo pairs was validated using $\mathrm{MeX}$ commercial software (Alicona Imaging $\mathrm{GmbH}$, Grambach, Graz, Austria) on known geometries, such as Vickers microhardness indents.

\section{RESULTS AND DISCUSSION}

\section{A. Fatigue Lifetime}

Fatigue failures in the range of $10^{6}$ to $10^{9}$ cycles were observed, as shown in Figure 4. Cracks initiated from surface and subsurface locations, as indicated by the open and closed data points, respectively. Data are shown for the two frequencies investigated: $20 \mathrm{~Hz}$ and $20 \mathrm{kHz}$, and all tests were cycled at a load ratio of 0.05 . The $20 \mathrm{~Hz}$ tests were conducted at stress levels $\left(\sigma_{\max }\right)$ of $820 \mathrm{MPa}$ and higher at AFRL. ${ }^{[23]}$ Ultrasonic-frequency fatigue testing was completed at $20 \mathrm{kHz}$ at stresses $\left(\sigma_{\max }\right)$ of $700 \mathrm{MPa}$ and below. ${ }^{[24]}$ Although the stress levels do not overlap, the data follow the same trend as expected for a typical SN curve. This indicates that there is no appreciable frequency effect on fatigue lifetime between testing frequencies of $20 \mathrm{kHz}$ and $20 \mathrm{~Hz}$. This is 


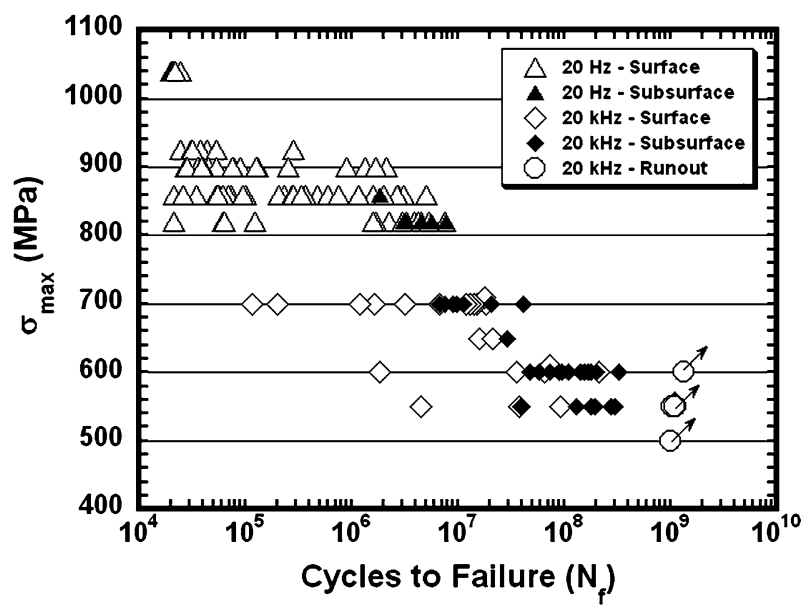

Fig. 4- SN curve displaying the fatigue lifetimes of specimens tested at ultrasonic frequencies and conventional frequencies. ${ }^{[23]}$

consistent with the findings of Paparikicou et al., ${ }^{[25]}$ who also observed a negligible effect of test frequency on the fatigue lifetimes of an $\alpha+\beta$ titanium alloy.

Additionally, there was an increased likelihood of subsurface-crack initiation as the stress level is decreased, which was also consistent across the testing frequencies. At ultrasonic frequencies, surface-crack initiation was observed approximately $80 \mathrm{pct}$ of the time for the highest stress level investigated (700 MPa), while at the lowest stress level (550 MPa), only 20 pct of the specimens failed from a surface-initiated fatigue crack. Specimens that failed by surface-crack initiation typically tended to have shorter lifetimes than those that failed from subsurface-crack initiation. However, in a few cases, surface-initiated failures were observed to have similar lifetimes as specimens that failed from subsurface-crack initiation sites, consistent with other investigations of fatigue in $\alpha+\beta$ titanium alloys. ${ }^{[35]}$

\section{B. Fractography}

Fractographs of typical crack-initiation sites in surface and subsurface locations are compared in Figure 5. In all cases, facets are observed at the site of crack initiation, and their size is commensurate with the larger $\alpha_{p}$ grains. The facets are presumed to form by the fatigue fracture of $\alpha_{p}$ grains along a preferred crystallographic plane and are referred to here as $\alpha_{p}$ facets. The average $\alpha_{p}$ grain size is approximately $4 \mu \mathrm{m}$, as measured from a random two-dimensional (2-D) section, while the average facet size is $5.3 \mu \mathrm{m}$. The histogram of $\alpha_{p}$-facet size is overlaid on the $\alpha_{p}$ grain size histogram in Figure 2. The $\alpha_{p}$-facet sizes were measured from SEM micrographs, and it is noted that facets are actually 3-D features projected onto a 2-D micrograph; i.e., the true size of the facets is larger than is represented in the histogram. The angle of the facet normal with respect to the fracture surface was not determined for every facet, and therefore, it is not possible to determine the true diameter of the facets. However, the importance of these measurements remains; facets form in $\alpha_{p}$ grains that are slightly
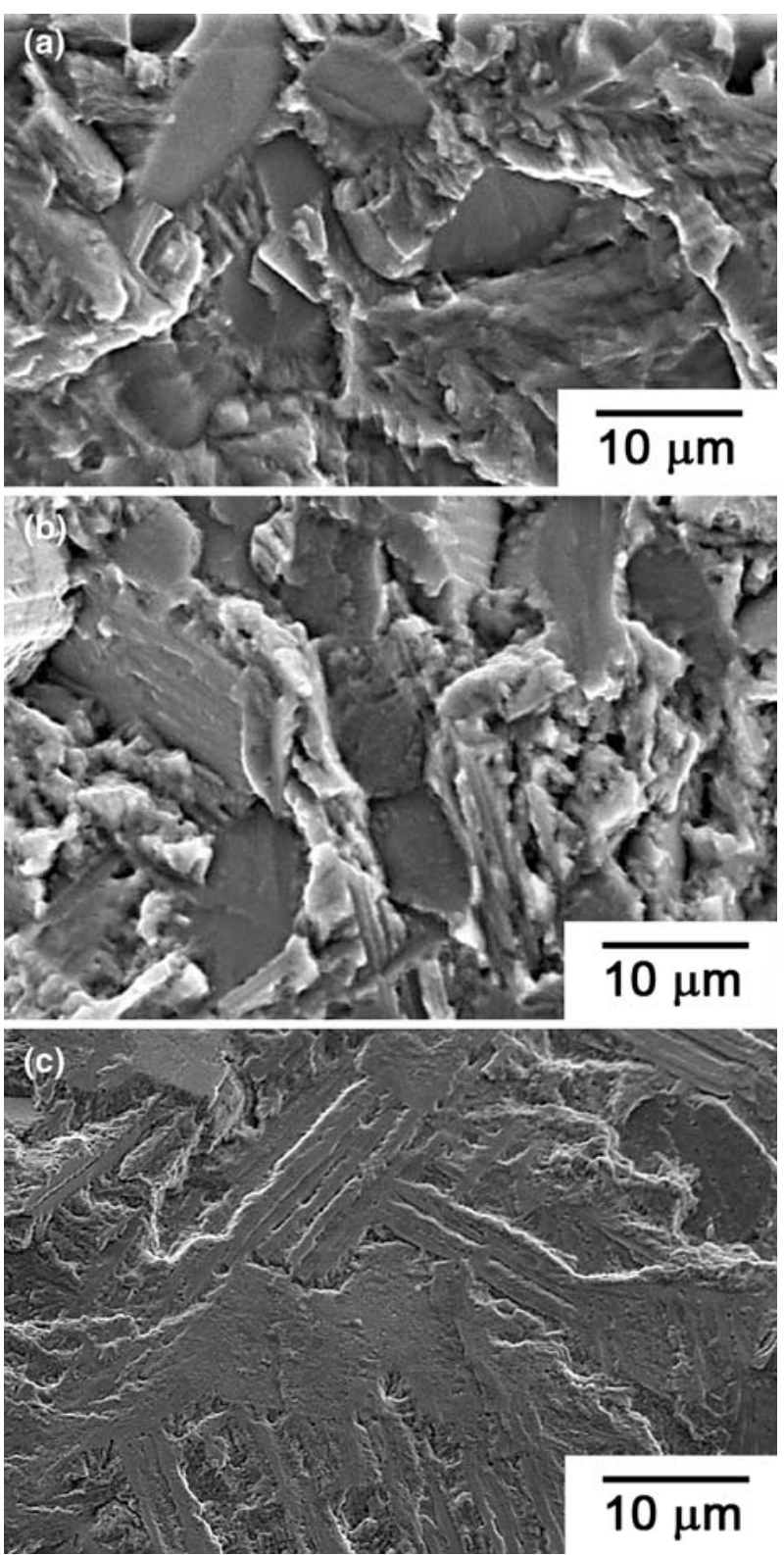

Fig. 5-Fractographs displaying examples of the three types of fracture surfaces: (a) surface, $(b)$ isolated subsurface faceting, and $(c)$ macroscopically planar subsurface crack-initiation sites.

larger than average but clearly do not fall into the tails of the grain-size distribution.

Failed specimens have been classified into three categories based on the appearance of the fracture surface near the crack-initiation site: surface, isolated subsurface faceting, and macroscopically planar subsurface sites. In the case of surface-crack initiation and subsurface-crack initiation with isolated facets, individual $\alpha_{p}$ facets are observed on the fracture surface, as shown in Figures 5(a) and (b), respectively. Figure 5(c) illustrates the third type of crack-initiation site, which consists of a macroscopically planar region that is occasionally observed in subsurface-crack initiation. This type of crack initiation spans a number of $\alpha_{p}$ grains and transformed $\beta$ regions, and the crack appears 
to form along the same plane relative to the loading axis in each of these grains. Upon closer inspection of these initiation sites, evidence of ductility is apparent within these large flat regions. Thus, it is not appropriate to call them facets because they are not truly planar. Crack initiation was classified as surface if the $\alpha_{p}$ facets intersected the specimen surface. Figure 6 displays the fatigue lifetimes where the data points have been classified into three different groups. Surface-crack initiation generally leads to the shortest lifetimes. However, the lifetimes of specimens failing by the two types of subsurface crack-initiation mechanisms are not significantly different.

Subsurface-crack initiation has been observed in a number of fatigue studies on $\alpha+\beta$ titanium alloys. ${ }^{[10,23,32-35]}$ The competition between surface and subsurface crack-initiation sites has alternately been attributed to the specimen surface to volume ratio, ${ }^{[27]}$ the presence of compressive residual stresses on the surface, ${ }^{[34]}$ environmental effects, ${ }^{[26]}$ and the relative ease with which grains can deform at a free surface as compared to the specimen interior.

In the regime of $\mathrm{VHCF}$, only certain microstructural neighborhoods are susceptible to fatigue-damage accumulation that leads to crack initiation, and these microstructural configurations do not necessarily exist at the specimen surface. This idea was first put forth by Mughrabi, ${ }^{[27]}$ and Jha and Larsen $^{[28]}$ subsequently proposed that different microstructural neighborhoods may be in competition with one another to initiate the dominant fatigue crack. In the current work, it appears that there may be a number of different microstructural regions in each sample that may initiate a fatigue crack; however, only the site that accumulates fatigue damage most rapidly will ultimately lead to fatigue-crack initiation. The fact that three characteristic crack-initiation sites have been observed at the same stress level indicates that there is competition between different microstructural neighborhoods for crack initiation. The evidence suggests that if there is not a suitable group of $\alpha_{p}$ grains

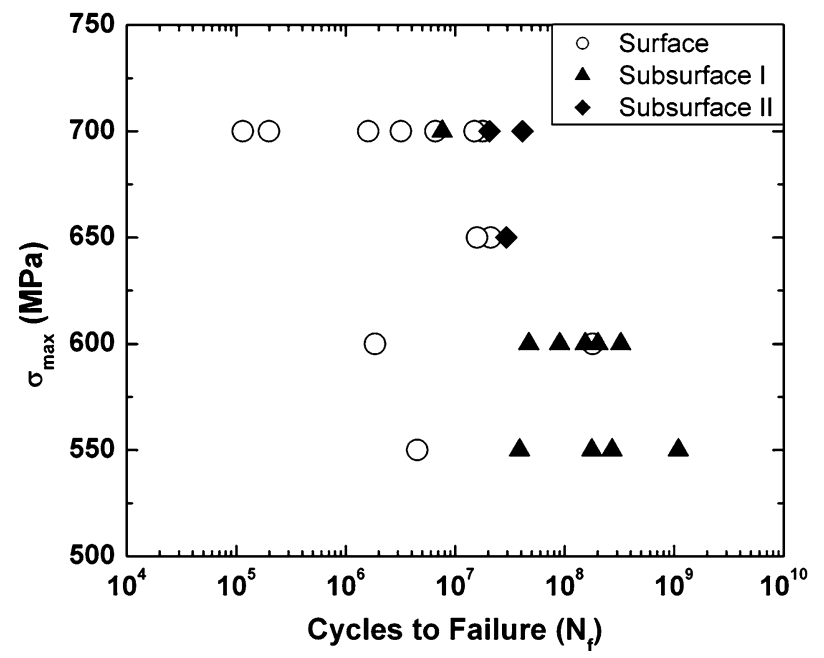

Fig. 6-SN curve displaying only ultrasonic-frequency $(20 \mathrm{kHz})$ data with initiation types distinguished. near the specimen surface, then a crack will initiate from the specimen interior, and the presence of different microstructural neighborhoods in the interior will cause a subsurface-initiation site with either isolated facets or with a macroscopically planar region. The occurrence of $\alpha_{p}$ facets at the crack-initiation sites indicates that $\alpha_{p}$ grains are influential in accumulating fatigue damage and subsequent fatigue-crack initiation. Similar observations led to speculation $^{[29]}$ that specific spatial and crystallographic orientations of $\alpha_{p}$ grains are required for fatigue cracks to initiate.

\section{Spatial Clustering of $\alpha_{p}$ Grains}

As illustrated by the highlighted features in Figure 7 , there is a higher tendency for faceted fracture of $\alpha_{p}$ grains near the site of fatigue-crack initiation. To characterize the spatial distribution of $\alpha_{p}$ grains and to determine whether this influenced fatigue-crack initiation in the current work, the area fraction of $\alpha_{p}$ facets was measured from fracture surfaces. The results are shown in Figure 8, where the area fraction of the fracture surface covered by facets is plotted as a function of the crack-tip driving force. The stress-intensity values on the abscissa were calculated using the Newman $\mathrm{Raju}^{[30]}$ stress-intensity solutions for surface cracks, while the Murakami ${ }^{[31]}$ solutions were used for subsurface cracks. The thick bounding lines in the plot represent the extremes of $\alpha_{p}$-grain spatial distribution in the general microstructure, i.e., the most clustered regions and the regions nearly devoid of $\alpha_{p}$ grains. As larger areas are probed, the area fraction of $\alpha_{p}$ grains, which is represented by these bounding lines, converges to the global measurement of an $\alpha_{p}$ area fraction of 27 pct, as indicated by the horizontal dotted line. Open data points represent failure by surface initiation, while closed data points mark the area fraction of facets from specimens that failed by subsurface-crack initiation. The legends in the plots indicate the lifetime of specimens that have been examined with this analysis. These data have been dissected in two different ways to examine

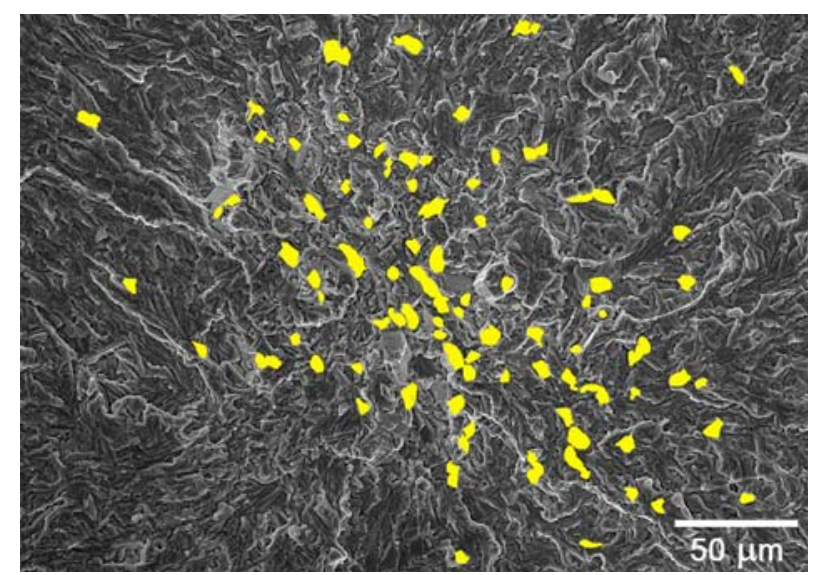

Fig. 7-A typical fractograph displaying isolated subsurface faceting where the facets have been highlighted. Color figure available online. 


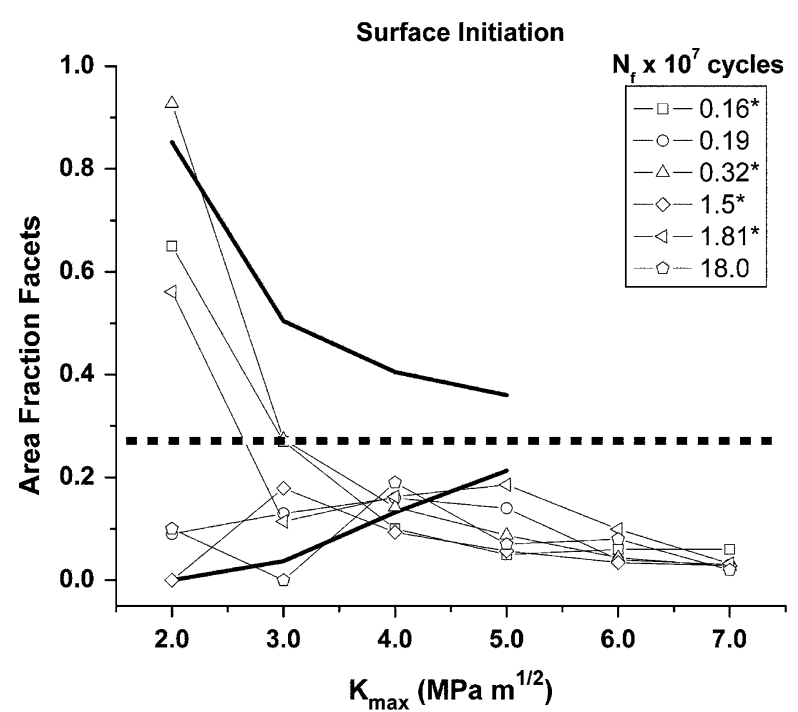

(a)

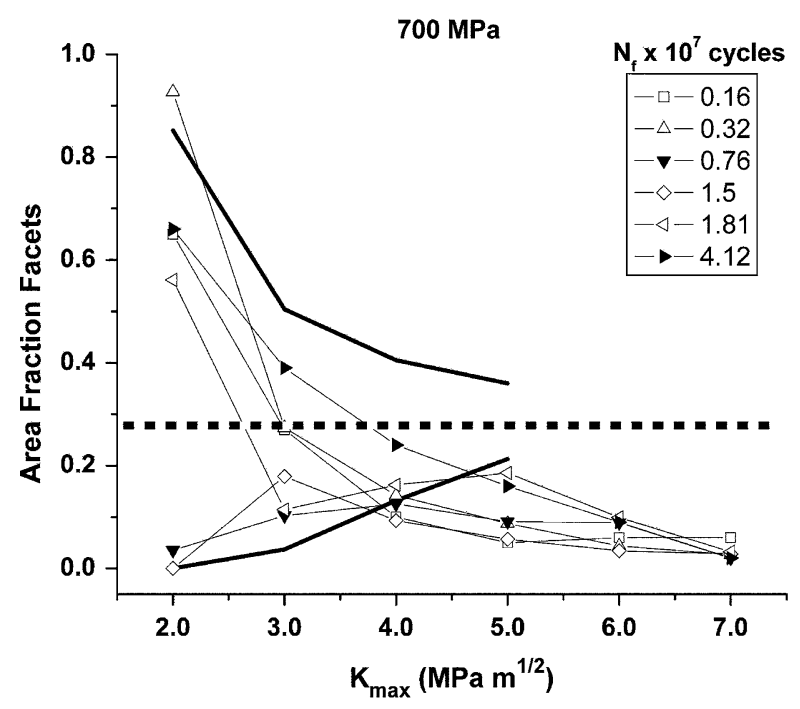

(c)

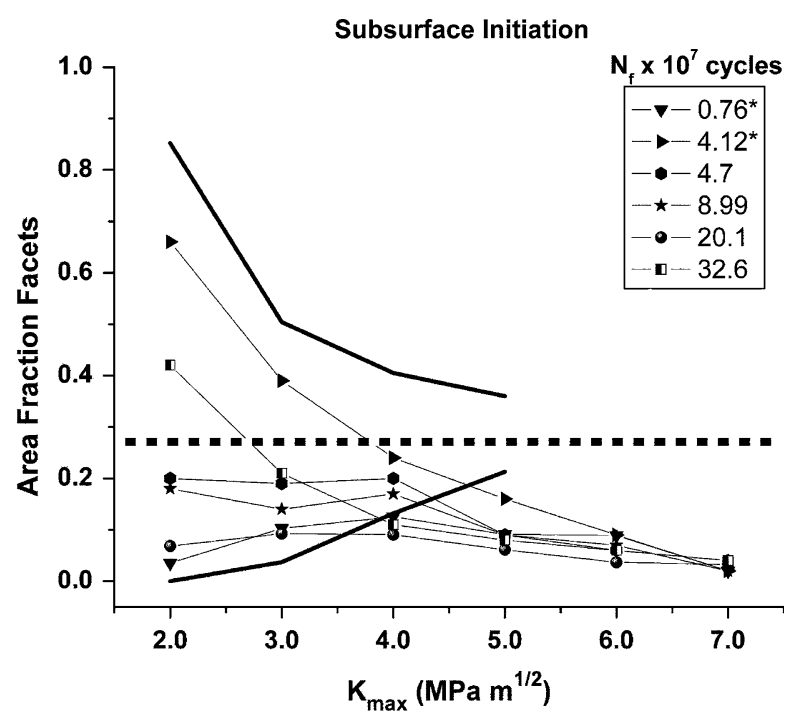

(b)

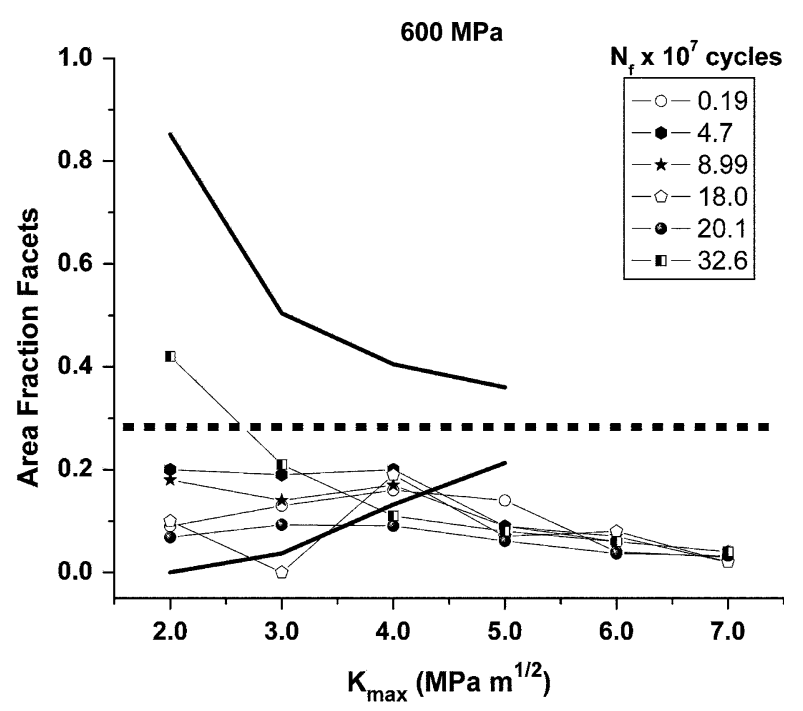

(d)

Fig. 8-Area-fraction clustering plots for $(a)$ surface-crack initiation, $(b)$ isolated subsurface faceting, $(c)$ failures from testing at $\left(\sigma_{\mathrm{max}}\right) 700 \mathrm{MPa}$, and (d) $600 \mathrm{MPa}$. The dark bounding lines depict the extremes of spatial orientations of $\alpha_{p}$ grains within the nominal microstructure.

differences in faceting between surface vs subsurfacecrack initiation, as well as the effects of stress level. The plots in Figures 8(a) and (b) illustrate the area fraction of faceting in surface- and subsurface-initiated failures, respectively. Figure 8(c) displays the area fraction of facets with respect to the presumed crack size for specimens tested at $700 \mathrm{MPa}\left(\sigma_{\max }\right)$, while Figure $8(\mathrm{~d})$ shows this data for specimens tested at $600 \mathrm{MPa}\left(\sigma_{\max }\right)$.

A number of observations can be drawn from these plots. First, the area fraction of $\alpha_{p}$ facets typically decreases as material farther from the crack-initiation site is considered. As the facet-formation process is suspected to result from fracture of $\alpha_{p}$ grains on crystallographic planes favorable for slip, the apparent lack of faceting for large crack sizes is expected because long cracks are not expected to propagate in a crystallographic manner. The local microstructure is known to influence crack initiation and small-crack growth ${ }^{[11,17,29]}$ therefore, more facets are expected to form in these regions than in regions where long crackgrowth conditions apply.

The results suggest that there is no critical value of spatial clustering of $\alpha_{p}$ that must be met for cracks to initiate. In some cases, the $\alpha_{p}$ facets are much more dispersed at the site of crack initiation than the $\alpha_{p}$ grains are in the general microstructure, while in other samples, the degree of faceting at the initiation site is markedly higher than the average $\alpha_{p}$-grain distribution. Thus, the spatial distribution of $\alpha_{p}$ grains alone does not determine where cracks will initiate in the general microstructure. Additionally, the lifetimes of specimens do not correlate with the spatial distribution of $\alpha_{p}$ at the crack-initiation sites. Assuming that the majority of $\alpha_{p}$ grains that the fatigue-crack encounters fail by faceted 
fracture, this suggests that the area fraction of faceting is not indicative of the rate of fatigue-damage accumulation or the degree of difficulty to initiate a fatigue crack in these microstructural regions. As the plots in Figures 8(a) and (b) illustrate, there is no discernable difference in the degree of faceting between surface- and subsurface-crack initiations. It is apparent that, in general, more faceting is observed at the crack-initiation sites for higher $\sigma_{\max }$, as shown in Figure 8(c) and (d). If faceting resulted from crystallographic propagation of short fatigue cracks, this trend would be expected to be reversed. Therefore, this finding suggests that the higher resolved stresses on the basal and prism slip systems in unfavorably oriented grains may cause slip to be activated in grains that would not otherwise contribute to the damage-accumulation process. As a result, a larger volume of material could contribute to the crackinitiation process at higher stress levels.

\section{Spatial Orientation of Facets}

A number of researchers ${ }^{[32-36]}$ have found that facets at the crack-initiation site are typically oriented normal to the tensile axis. This led some researchers ${ }^{[35,36]}$ to speculate that stress redistribution within the microstructure can lead to activation of a pseudocleavage mechanism of fatigue-crack initiation in which it is proposed that grains oriented for slip may induce stress in adjacent grains. As the stress in this neighboring grain increases, it will eventually fail by a cleavage-type failure mechanism. In the current study, the larger facets at the crack-initiation site are typically oriented for high resolved shear stress (facet normal is inclined at an angle of greater than $30 \mathrm{deg}$ with respect to the fracturesurface plane). In Figure 9, the facets that have been measured by this technique are highlighted, and the labels correspond to the numbers in Table I. Facets 1 and 2 have the ideal spatial orientation for slip. Facet 4 is notable because its normal forms only a 13 deg angle with respect to the tensile axis. This observation agrees with the work of Williams et al., ${ }^{[36]}$ in which basal slip was observed to occur in TiAl single crystals where the

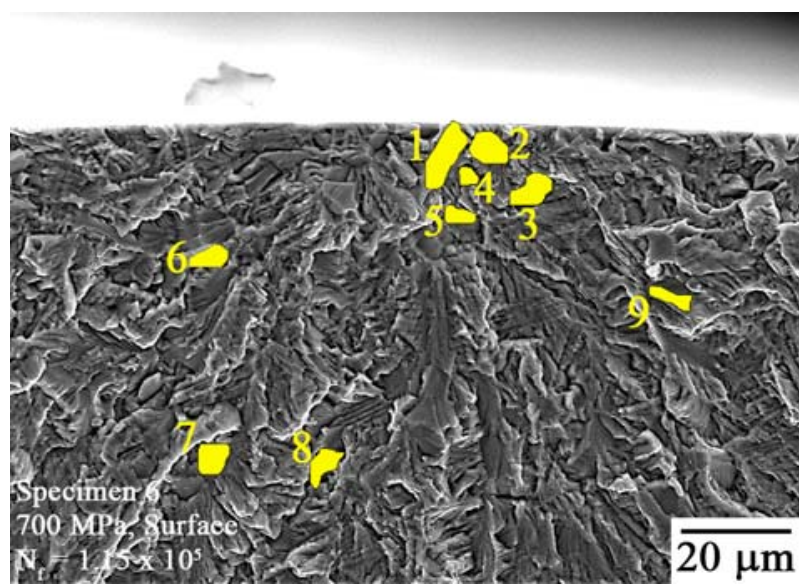

Fig. 9-A fractograph indicating the facets that have been measured with MeX. Color figure available online.
Table I. Spatial Orientation of Facets with Respect to Fracture Surface (in Deg)

\begin{tabular}{lrrrrrrrrrr}
\hline Facet Number & 1 & 2 & 3 & 4 & $5 \mathrm{a}$ & $5 \mathrm{~b}$ & 6 & 7 & 8 & 9 \\
Angle & 46 & 45 & 39 & 19 & 26 & 35 & 33 & 31 & 32 & 21 \\
\hline
\end{tabular}

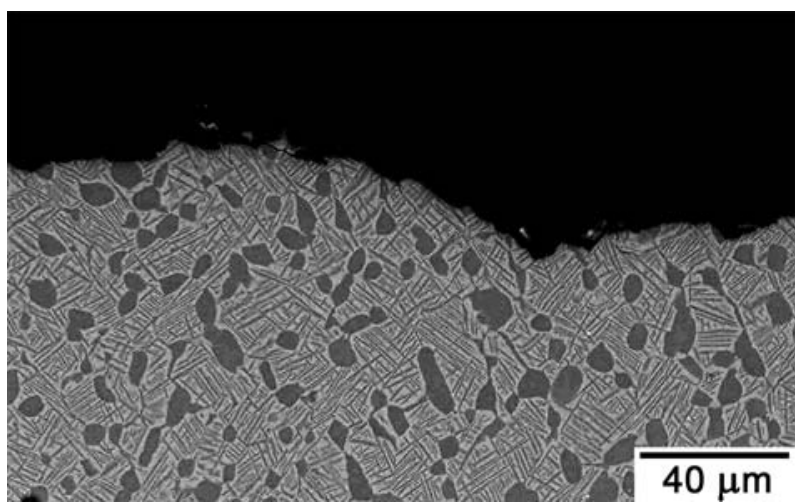

Fig. 10 - Subsurface crack-initiation site after sectioning to expose a plane just below the crack-initiation site.

basal plane was only 13 to $15 \mathrm{deg}$ from a perpendicular orientation with respect to the tensile axis.

Specimens were sectioned to expose the microstructure below the crack-initiation site as shown in Figure 3, which is a schematic that depicts the sectioning plane cutting through the crack-initiation site. An SEM micrograph of a specimen that was prepared by this sectioning procedure is shown in Figure 10, which illustrates that the crack plane is not perpendicular to the loading axis at the crack-initiation site. The tensile axis in this image is vertical in the plane of the page. From this image, it is apparent that the crack-initiation process is caused by slip because this plane is oriented for a high resolved shear stress. These results indicate that for this alloy and test condition, fatigue cracks initiate by a slip process and not by pseudocleavage, as observed in other investigations ${ }^{[17,37]}$ of the fatigue behavior in alpha + beta titanium alloys.

\section{E. Crystallographic Orientation of Crack Initiating Region}

The crystallographic orientation of alpha grains at the site of crack initiation was determined using OIM on samples sectioned, as shown in Figure 3. Because the spatial orientation of the facets with respect to the tensile axis was known, OIM was used to determine if the facet planes corresponded to a specific crystallographic plane. The facets observed on the fracture surface were determined to be basal planes of the equiaxed $\alpha_{p}$ grains. The inverse pole figure (IPF) map from an OIM scan is shown in Figure 11. The schematic in Figure 3 illustrates the reference frame for this image. The term RD corresponds to the tensile axis, while ND is normal to the polished surface. Although the micrograph displays the microstructure as viewed from the RD-TD plane, the orientations that these colors 


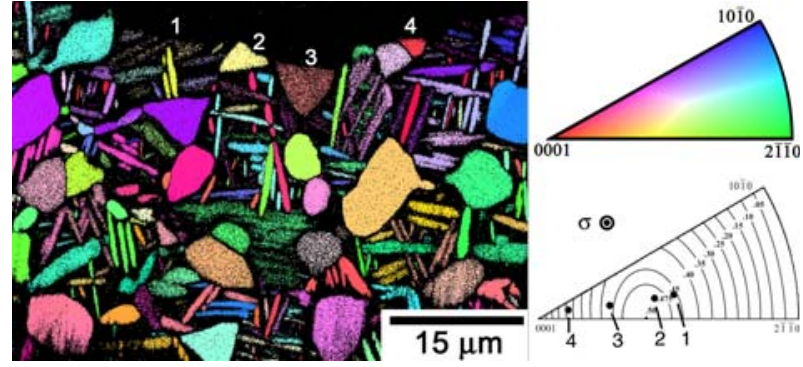

Fig. 11-Illustration of the crystallographic orientation of $\alpha_{p}$ grains what have failed by faceted fracture. The spatial orientation of the facet poles have been plotted in the IPF, which also shows the contour lines of the Schmid factor for basal slip. Color figure available online.

Table II. Orientation of Facets (in Deg)

\begin{tabular}{lrrrr}
\hline Facet Number & $1 *$ & 2 & 3 & 4 \\
$\begin{array}{l}\text { Spatial orientation } \\
\text { (with respect to tensile axis) }\end{array}$ & 44 & 42 & 25 & 15 \\
$\begin{array}{l}\text { Crystallographic orientation } \\
\text { ([0001] with respect to tensile axis) }\end{array}$ & 51 & 50 & 30 & 13 \\
\hline
\end{tabular}

* Facet 1 is not a $\alpha_{p}$ facet, but a facet that formed from the fracture of a transformed beta region.

represent are shown from the perspective of viewing down the RD axis or, equivalently, the tensile axis. The colors in the IPF map correspond to the colors in the unit triangle shown in the top right of the figure. The orientations of the four indicated features are also plotted in the unit triangle in the bottom right of Figure 11, which displays the Schmid factor isocurves for basal slip. These grains have high Schmid factors for basal slip, which indicates that the facets formed by slip on a basal plane. Table II lists the spatial orientation of facets with respect to the loading axis (RD) and the crystallographic angle with respect to the basal pole for each of the facets marked in the micrograph. As shown in Table II, the spatial and crystallographic angles follow the same trend, and the facet normal is aligned with the basal pole of these grains. Facet 1 is a unique case because it is not a facet which formed in an $\alpha_{p}$ grain. As shown in the IPF map in Figure 11, this feature, which appears as a facet on the fracture surface, is in fact a region of transformed beta material. The crystallographic and spatial measurements still indicate that this failure results in a facet parallel to the basal plane. The repeatability of the OIM measurements is reliable to within $\pm 3 \mathrm{deg}$, which agrees with what Davidson et al. ${ }^{[11]}$ found, and the accuracy of the measurements from stereo pairs was found to be roughly the same. Therefore, within the accuracy of the experimental techniques, the facets appear to form within a few degrees of the basal plane. Facets have also been examined in surface-initiated failures, and the facets form along the basal plane in a $\alpha_{p}$ grain oriented for slip. These results indicate that basal slip is operative in a number of grains at the crack-initiation site, and this raises the question of how many $\alpha_{p}$ grains are oriented for basal slip in these regions.

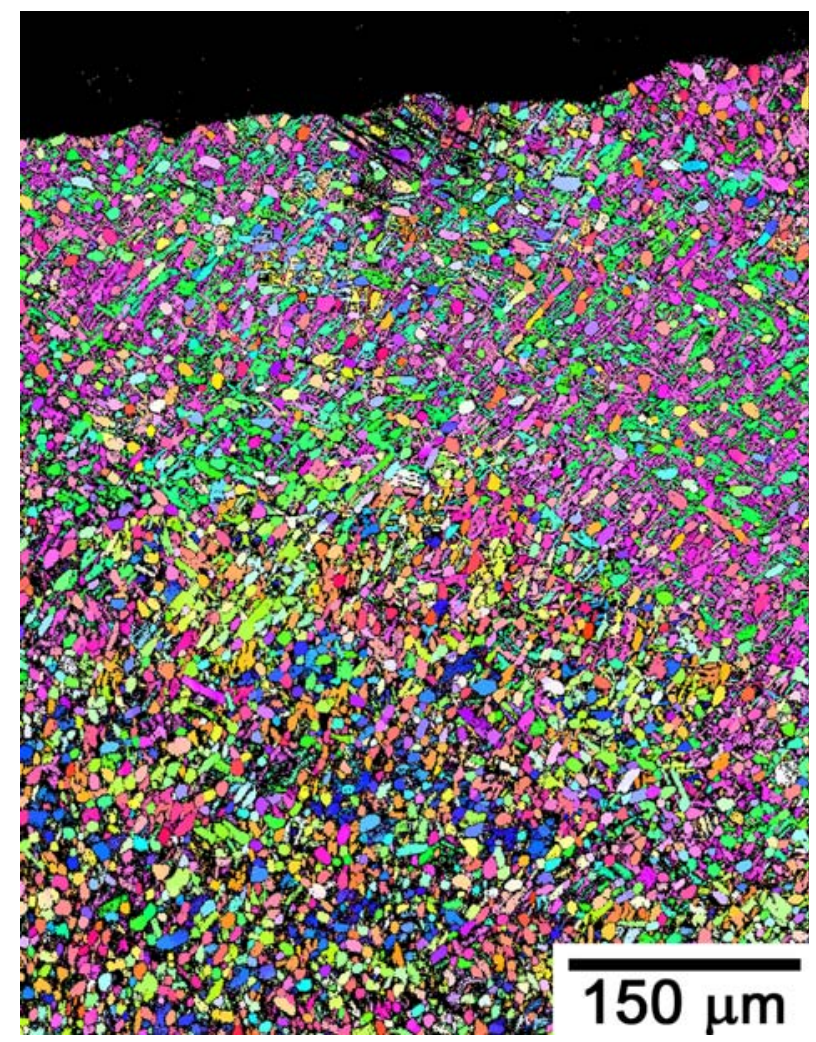

Fig. 12-Example IPF map from an OIM scan displaying the texture of the $\alpha$ phase near the crack-initiation site. Color figure available online.

Observation of the material around the crack-initiation site reveals that the majority of alpha-phase material, including lath $\alpha$ and equiaxed $\alpha_{p}$ grains, is oriented for either basal or prism slip. An IPF map of the RD-TD plane for a typical crack-initiation site is shown in Figure 12. LeBiavant et al. ${ }^{[7]}$ argue that the texture of these regions promotes plastic deformation in the crack-initiating grains. The likelihood of finding a group of $\alpha_{p}$ grains with similar crystallographic orientations suitable for basal slip is believed to be higher in these textured regions as opposed to a random area with no preferred (i.e., random) crystallographic texture. ${ }^{[7,17]}$ As shown in Figure 12, the textured regions are as large as 300 to $500 \mu \mathrm{m}$ in size, which is the approximate dimension of the initial $\beta$-grain size.

Random areas, far from the crack-initiation sites, were sectioned to expose the RD-TD plane as described earlier, and they were examined using OIM to determine if a preferred crystallographic texture also exists in general microstructural areas. Figure 13 illustrates the texture in a randomly selected region of material for a much larger area. In this image, areas with a high degree of preferred texture suitable for basal and prism slip are observed in the nominal microstructure. These regions of preferred texture correspond to the beta-grain texture and morphology. The length scale of these textured regions appears to be 300 to $500 \mu \mathrm{m}$ in size, and this is approximately the size of the prior beta grains, which indicates that these textured regions formed in the initial $\beta$-processing steps. 


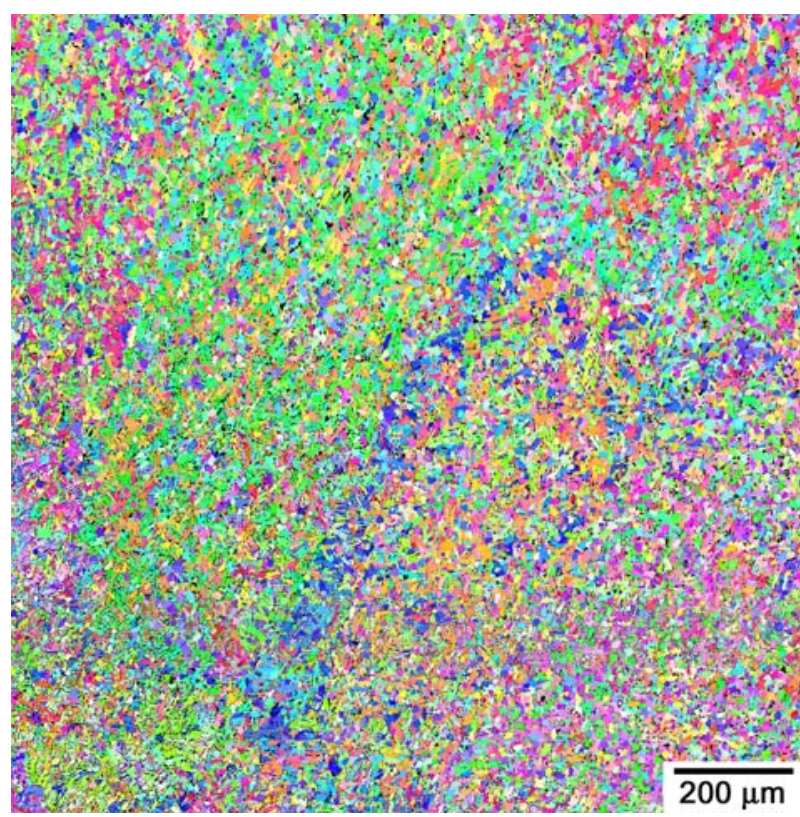

Fig. 13-A typical IPF map from an OIM scan that illustrates large regions of similarly oriented material commonly found in the general microstructure. Color figure available online.

Thus, it appears that the presence of a preferred texture suitable for basal and prism slip is a necessary, but not a sufficient, condition for crack initiation. In these regions of preferred texture, it is clear that the majority of the $\alpha$-phase material shares the same crystallographic orientation. However, the strength of the preferred texture will affect the resistance to fatiguecrack initiation. In other words, a weakly textured region of material will not promote crack initiation and propagation as successfully as a suitably oriented strongly textured region might. It has been established that regions of material with preferred texture for basal and prism slip are found at the crack-initiation site. However, quantification of these variations in texture intensity has not been completed, and this will be examined in future work.

Thus far, the texture of the $\alpha$ phase, i.e., the lath $\alpha$ and the $\alpha_{p}$ grains, has been considered as one. However, the texture of the lath $\alpha$ and equiaxed $\alpha_{p}$ phases should be considered separately because the correlation in the textures of these phases will affect the ease of slip transmission between grains. The lath $\alpha$ maintain a Burgers orientation relationship with the $\beta$ phase, whereby the basal (0001) plane of the $\alpha$ phase is parallel to the (110) plane of the $\beta$ phase. ${ }^{[38]}$ Due to the spherodization process which forms the $\alpha_{p}$ grains, it is generally assumed that equiaxed $\alpha_{p}$ are not crystallographically related to the prior $\beta$-grain orientation. ${ }^{[39]}$ However, Woodfield et al. ${ }^{12]}$ note that strains on the order of $\varepsilon=1$ are required to dynamically spheroidize the $\alpha$ laths to form $\alpha_{p}$ grains, but this strain still may not be high enough to cause recrystallization of the $\alpha$ lath material as they spheroidize. Therefore, the $\alpha_{p}$ grains may, in fact, share a crystallographic-orientation relationship with the prior $\beta$, and hence, the lath $\alpha$ and slip transmission across phases may not be hindered by the grain boundaries. Quantification of these individual texture components remains as future work.

Figure 14 is a schematic that depicts the proposed mechanism of subsurface fatigue-crack initiation that is consistent with the observations in this study. The $\alpha_{p}$ grains are shown in the schematic, while the lath $\alpha$ is not drawn but assumed to have the same crystallographic orientation as the $\alpha_{p}$ grains. The larger grayscale regions are drawn to illustrate the beta grains. Each of the images depicts the stages of slip accumulation in $\alpha_{p}$ grains, which ultimately leads to fatigue-crack initiation. Figure 14(a) illustrates the general microstructure, which is free of deformation and slip accumulation, while Figure 14(b) depicts the accumulation of slip in a few $\alpha_{p}$ grains. Figure 14(c) shows the intensification of slip in those initial grains and the initiation of slip deformation in a few adjacent $\alpha_{p}$ grains. The last stage, as shown in Figure 14(d), indicates that a crack has initiated from the linkup of these related slip events. This proposed mechanism is based on the fractographic evidence that crack initiation takes place across a number of $\alpha_{p}$ grains, typically over a region of 40 to $70 \mu \mathrm{m}$ in diameter. The facets that form on the fracture surface result from slip deformation on, and eventual separation of, the basal plane in $\alpha_{p}$ grains. Additionally, as shown in Figure 12, it appears that these $\alpha_{p}$ grains are contained within one large beta grain and that many of them have similar crystallographic orientations. Because the majority of $\alpha_{p}$ grains within these regions have similar crystallographic orientations, it is presumed that if slip can accumulate in one of these grains, it will likely be able to accumulate in a number of $\alpha_{p}$ grains within the beta grain. Likewise, the lath $\alpha$ are known to be oriented for slip deformation in these regions and are presumed to accumulate slip and contribute to the general fatigue-damage accumulation in these microstructural regions. This mechanism of crack initiation is applicable to all types of initiation sites that were observed. For the macroscopically planar fracture surfaces, the $\alpha_{p}$ grains and lath $\alpha$ are presumed to be aligned such that the activation of slip in all of the grains occurs across the same macroscopic plane. In the case of crack initiation from isolated facets, the spatial- and crystallographic-orientation measurements indicate that the basal planes within these grains, while still oriented for slip, are misaligned with respect to each other, and as a result, individual facets are observed.

A similar explanation for crack initiation has been postulated in the work of LeBiavant et al. ${ }^{[7]}$ on the microstructural influences of bending fatigue in Ti-6Al$4 \mathrm{~V}$. They observed that cracks initiate in macrozones, which are defined as regions of material in which the majority of $\alpha_{p}$ grains have a similar orientation. In the macrozone that initiated the dominant fatigue crack, multiple microcracks were observed. They postulated that the dominant fatigue crack grew out of these macrozones due to microcrack coalescence. In the current work, there is no evidence of slip offsets or microcracks in $\alpha_{p}$ grains, aside from those on the fracture surface. Fatigue damage is believed to accumulate throughout these similarly oriented regions of 


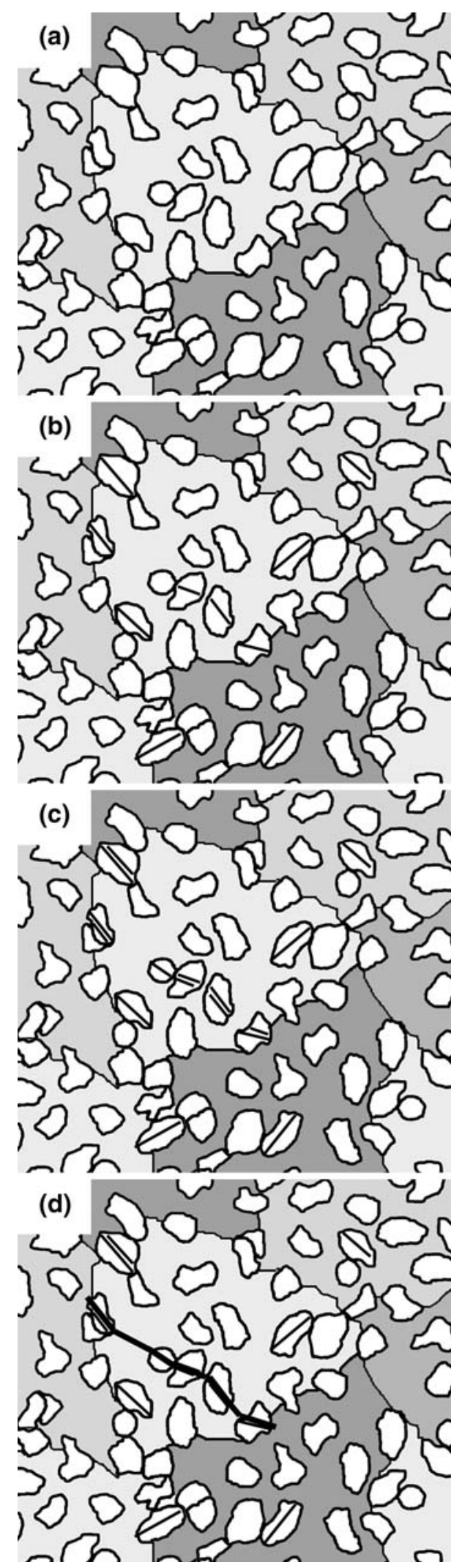

Fig. 14-A schematic depiction of the crack-initiation process: $(a)$ illustration of the microstructure before any fatigue cycles have been applied; $(b)$ depiction of slip accumulation in a few favorably oriented $\alpha_{p}$ grains; (c) demonstration of the intensification of slip within certain $\alpha_{p}$ grains and slip accumulation within neighboring grains, as well; and (d) illustration of the formation of a crack within the microstructure. material, and slip activity in neighboring grains may facilitate crack initiation and growth. However, no evidence of other cracks is observed; thus, crack coalescence is not believed to significantly affect crackgrowth rates. This difference may be due to the fact that LeBiavant et al. ${ }^{[7]}$ performed their tests at $800 \mathrm{MPa}$ in a material with a yield strength of $850 \mathrm{MPa}$, while the current investigation focused on the fatigue behavior at much lower stresses in the range of 0.4 to 0.6 of $\sigma_{Y S}$, where it is unlikely that slip activity would intensify to such an extent that fatigue cracks would initiate in other $\alpha_{p}$ grains.

The proposed mechanism can be generalized to explain the process of fatigue-crack initiation for the three types of crack-initiation sites that were observed. In the case of surface-crack initiation, faceted fracture of $\alpha_{p}$ grains is still observed, and the mechanism is essentially the same. However, the size of the faceted region is smaller for surface failures than it is for subsurface crack-initiation sites. Therefore, the same mechanism is believed to be applicable, but fewer $\alpha_{p}$ grains are required to accumulate cyclic strain because surface-connected cracks can be smaller than subsurface cracks and still propagate at the same rate due to differences in stress intensity and environmental contributions at these sites. In subsurface macroscopically planar failures, the whole faceted region has the same spatial orientation with respect to the loading axis. This indicates that the $\alpha_{p}$ grains and lath- $\alpha$ colonies within the crack-initiation region all have a similar crystallographic orientation. The noticeable feature of these initiation sites is that they appear to form from the faceted fracture of transformed beta regions of material. There are clearly $\alpha_{p}$ grains in that area; however, the slip planes of $\alpha_{p}$ grains and transformed beta regions of material must be aligned such that the grain boundaries between these phases are not distinguishable on the fracture surface. For these types of failures, it is still thought that slip must accumulate in a number of $\alpha_{p}$ grains or transformed beta regions in order to initiate a fatigue crack.

\section{CONCLUSIONS}

Ultrasonic fatigue at a load ratio of 0.05 and stresses $\left(\sigma_{\max }\right)$ in the range of 500 to $700 \mathrm{MPa}$ has been shown to produce failures that display similar trends in lifetime and fractographic appearance with respect to conventional-frequency fatigue. Cracks initiate in larger than average-sized $\alpha_{p}$ grains by strain localization resulting from basal and prism slip. The initiation process leads to microcrack formation in the $\alpha_{p}$ grains parallel to the basal plane. Pseudocleavage is not operative because facets are oriented for slip on rational crystallographic planes. Cracks typically form in $\alpha_{p}$ grains with similar orientations that favor slip on basal planes in which the basal planes are only slightly misaligned in neighboring grains. These microstructural configurations appear to be found more often in textured regions. It is believed that this allows for relatively easy slip transmission between neighboring $\alpha_{p}$ grains. However, spatial 
clustering of $\alpha_{p}$ grains has been proven not to be the distinguishing microstructural feature at crack-initiation sites. Crack-initiation sites have a preferred texture, and it is observed that a majority of the grains near the site are oriented for easy basal or prism $\langle a\rangle$ type slip. Analysis of the fatigue-lifetime data using probabilistic models of fatigue-crack initiation will be presented in a forthcoming article.

\section{ACKNOWLEDGMENTS}

The authors thank the AFOSR Metallic Materials Program (Project No. F49620-03-1-0069) for financial support. One of the authors (CJS) thanks the STEP program at the AFRL Materials and Manufacturing Directorate for funding. The authors also thank C. Torbet, University of Michigan, for technical assistance.

\section{REFERENCES}

1. C. Engler-Pinto, Jr., R. Frisch, Sr., J. Lasecki, H. Mayer, and J. Allison: in VHCF4, J. Allison, J.W. Jones, J. Larsen, and R. Ritchie, eds., TMS, Warrendale, PA, 2007, pp. 421-27.

2. C. Bathias: Fatigue Fract. Eng. Mater. Struct., 1999, vol. 22, pp. 559-65.

3. S. Nishijima and K. Kanazawa: Fatigue Fract. Eng. Mater. Struct., 1999, vol. 22 , pp. 601-07.

4. H. Mughrabi: Fatigue Fract. Eng. Mater. Struct., 1999, vol. 22, pp. 633-41.

5. P. Lukáš and L. Kunz: Fatigue Fract. Eng. Mater. Struct., 1999, vol. 22 , pp. $747-53$.

6. Y. Murakami, T. Nomoto, and T. Ueda: Fatigue Fract. Eng. Mater. Struct., 1999, vol. 22, pp. 581-90.

7. K. LeBiavant, S. Pommier, and C. Prioul: Fatigue Fract. Eng. Mater. Struct., 2002, vol. 25, pp. 527-45.

8. J.A. Hall: Int. J. Fatigue, 1997, vol. 31 (Suppl. 1), pp. S23-S37.

9. Y. Mahajan and H. Margolin: Metall. Trans. A, 1982, vol. 13A, pp. 257-68.

10. K.S. Ravi Chandran and S.K. Jha: Acta Mater., 2005, vol. 53, pp. $1867-81$.

11. D.L. Davidson, R.G. Tryon, M. Oja, R. Matthews, and K.S. Ravi Chandran: Metall. Mater. Trans. A, 2007, vol. 38A, pp. 2214-25.

12. A.P. Woodfield, M.D. Gorman, R.R. Corderman, J.A. Sutliff, and B. Yamrom: in Titanium '95, P.A. Blenkinsop, W.J. Evans, and H.M. Flower, eds., IOM, Birmingham, 1996, pp. 1116-23.

13. T.R. Bieler and S.L. Semiatin: Int. J. Plast., 2002, vol. 18, pp. 1165-89.

14. G. Lütjering: Mater. Sci. Eng., 1998, vol. 243A, pp. 32-45.

15. A.W. Bowen: Acta Metall., 1975, vol. 23, pp. 1401-09.

16. I. Bantounas, T. Lindley, D. Rugg, and D. Dye: Acta Mater., 2007, vol. 55, pp. 5655-65.
17. V. Sinha, J.E. Spowart, M.J. Mills, and J.C. Williams: Metall. Mater. Trans. A, 2006, vol. 37A, pp. 1507-18.

18. G. Lutjering and J.C. Williams: Titanium, Springer-Verlag, Berlin, 2003, pp. 182-85.

19. J.M. Larsen, J.R. Jira, and K.S. Ravi Chandran: in Small Crack Test Methods, ASTM STP 1149, J.M. Larsen and J.E. Allison, eds., ASTM, Philadelphia, PA, 1992, pp. 57-80.

20. A. Shyam, C.J. Torbet, S.K. Jha, J.M. Larsen, M.J. Caton, C.J. Szczepanski, T.M. Pollock, and J.W. Jones: in Superalloys 2004, K.A. Green, T.M. Pollock, H. Harada, T.E. Howson, R.C. Reed, J.J. Schirra, and S. Walston, eds., TMS, Warrendale, PA, 2004, pp. $259-68$.

21. C.J. Szczepanski, A. Shyam, S.K. Jha, J. Larsen, C.J. Torbet, S.J. Johnson, and J.W. Jones: in Materials Damage Prognosis, J.M. Larsen, L. Christodoulou, J.R. Calcaterra, M.L. Dent, M.M. Deriso, W.J. Hardman, J.W. Jones, and S.M. Russ, eds., TMS, Warrendale, PA, 2005, pp. 315-20.

22. J.Z. Yi, C.J. Torbet, Q. Feng, T.M. Pollock, and J.W. Jones: Mater. Sci. Eng., 2007, vol. 443 (A), pp. 142-49.

23. S.K. Jha, J.M. Larsen, A.H. Rosenberger, and G.A. Hartman: Scripta Mater., 2003, vol. 48, pp. 1637-42.

24. C.J. Szczepanski, S.K. Jha, J.M. Larsen, and J.W. Jones: in VHCF4, J. Allison, J.W. Jones, J. Larsen, and R. Ritchie, eds., TMS, Warrendale, PA, 2007, pp. 37-44.

25. M. Papakyriacou, H. Mayer, C. Pypen, H. Plenk, Jr., and S. Stanzl-Tschegg: Mater. Sci. Eng., 2001, vol. 308 (A), pp. 143-52.

26. J. Mendez, S. Mailly, and P. Villechaise: in Temperature-Fatigue Interactions, L. Remy and J. Petit, eds., ESIS TTP 29, Elsevier Press, Amsterdam, 2002, pp. 95-102.

27. H. Mughrabi: Fatigue Fract. Eng. Mater. Struct., 2002, vol. 25, pp. 755-64.

28. S.K. Jha and J.M. Larsen: in VHCF4, J. Allison, J.W. Jones, J. Larsen, and R. Ritchie, eds., TMS, Warrendale, PA, 2007, pp. $385-96$.

29. J.L. Gilbert and H.R. Piehler: Metall. Trans. A, 1993, vol. 24A, pp. 669-80.

30. J.C. Newman, Jr. and I.S. Raju: Eng. Fract. Mech., 1981, vol. 15, pp. 185-92.

31. Y. Murakami: Stress Intensity Factors Handbook, Pergamon Press, New York, NY, 1987, p. 668.

32. D.L. Davidson and D. Eylon: Metall. Trans. A, 1980, vol. 11A, pp. 837-43.

33. J.A. Ruppen, D. Eylon, and A.J. McEvily: Metall. Trans. A, 1980, vol. 11A, pp. 1072-75.

34. R.K. Nalla, B.L. Boyce, J.P. Campbell, J.O. Peters, and R.O. Ritchie: Metall. Mater. Trans. A, 2002, vol. 33A, pp. 899-918.

35. D.F. Neal and P.A. Blenkinsop: Acta Metall., 1976, vol. 24, pp. 59-63.

36. J.C. Williams, R.G. Baggerly, and N.E. Paton: Metall. Mater. Trans. A, 2002, vol. 33A, pp. 2015-26.

37. W.J. Evans and M.R. Bache: Int. J. Fatigue, 1994, vol. 16, pp. $443-52$.

38. W.G. Burgers: Physica, 1934, vol. 1, pp. 561-86.

39. H. Margolin, J.C. Williams, J.C. Chesnutt, and G. Lutjering: Titanium '80, Proc. 4th Int. Conf. Titanium, H. Kimura and O. Izumi, eds., TMS-AIME, Warrendale, PA, 1980, pp. 169-216. 